\title{
RANCANG BANGUN SISTEM INFORMASI KEPEGAWAIAN CUTI KARYAWAN DI PT. COLORPAK INDONESIA, TBK BERBASIS WEB
}

\author{
Nurdiana Handayani ${ }^{1}$, Dicky Suprapto ${ }^{2}$ \\ Program Studi Informatika \\ Fakultas Teknik Universitas Muhammadiyah Tangerang \\ Jl. Perintis Kemerdekaan 1/33 Cikokol Kota Tangerang \\ dieyan3@gmail.com, dicky.handju@ rocketmail.com
}

\begin{abstract}
Abstract - Specialized information systems in personnel data are a matter of special concern. This is related to the ease and effectiveness in the processing of employee data such as employee data entry, employee data editing, employee data search, employee data report either on screen or printed on paper, especially in employee information system Employee leave. Management of personnel information system employee leave at PT. Colorpak Indonesia, Tbk which is still less than the maximum, such as the employee must fill the form of leave and wait for approval of the boss and less accuracy of the amount of employee leave balance. So to overcome it required personnel information system employee leave better than the previous system in order to present employee personnel leave information complete and simplify in knowing the amount of leave used and employee leave balance. This research uses waterfall method and system design is implemented with Diagram Unified Modeling Language (UML). The expected final result is that the employee-based employee leave information system can overcome the system problems that run more leverage in the process of submission and employee leave employment approval, employee reporting reports employee leave and employee employee leave data searching easier. With this research is expected to help PT. Colorpak Indonesia, Tbk especially Human Resource division to develop staffing information system employee leave.
\end{abstract}

Keywords: Information Systems, Employment Leave Employees, Diagrams UML, Waterfall, Web

\section{PENDAHULUAN}

\section{A. Latar Belakang Masalah}

Di masa yang berbasiskan internet seperti saat ini, teknologi berbasis web sudah banyak digunakan untuk membantu proses bisnis di suatu perusahaan. Internet dapat memenuhi banyak kebutuhan pengelolaan informasi. Teknologi informasi menempati peranan utama dalam kehidupan masyarakat sekarang ini dan perkembangannya pun sangat pesat sekali, dan kita dapat mengolah dan mendapatkan informasi dengan cepat, tepat dan akurat. Saat ini sudah menjadi kebutuhan yang tidak dapat terelakkan bahwa sistem komputerisasi dapat memberi kemudahan dalam mencari informasi yang diinginkan, mengurangi terjadinya kesalahan

yang disebabkan oleh kelalaian manusia dan keamanan data pun lebih terjamin, penggunaan komputer dan sistem informasi yang optimal dan didukung dengan sumber daya manusia yang berkualitas dalam sebuah instansi/perusahaan akan menunjang efisiensi dan efektifitas kerja dalam mengolah data 
untuk mendapatkan informasi yang dibutuhkan.

Sistem informasi yang menangani khusus dalam data kepegawaian merupakan suatu hal yang harus mendapatkan perhatian khusus. Ini berkaitan dengan kemudahan dan efektifitas dalam pengolahan data pegawai seperti pemasukan data pegawai, pengeditan data pegawai, pencarian data pegawai, laporan data pegawai baik pada layar monitor maupun dicetak pada kertas,sehingga penanganan pengolahan data pegawai lebih efektif dan efisien baik dari segi waktu maupun biaya.

Oleh karena itu karyawan sebagai kaki tangan dan otak dari sebuah perusahaan perlu amat diperhatikan kesejahteraannya oleh manajemen perusahaan, misalnya: gaji, tunjangan-tunjangan, upah lembur, cuti, dan lain-lain seperti yang diatur dalam undangundang ketenagakerjaan yang dibuat oleh pemerintah

Cuti dapat digunakan oleh pegawai untuk tidak masuk kerja dengan alasan tertentu, misalkan refreshing, istirahat sakit, melahirkan, menunaikan agama, dan keperluan lain sesuai dengan ketentuan cuti pada masingmasing perusahan. Pengelolaan sistem informasi cuti karyawan di PT. Colorpak Indonesia, Tbk yang masih menggunakan cara manual yaitu mengisi form dalam bentuk kertas dalam melakukan pengajuan hak cuti karyawan kepada pihak Manajemen baik itu Manager maupun HRD. Oleh karena itu diperlukan sistem yang sudah terkomputerisasi dalam mengelola hak cuti karyawan serta untuk mempermudah para karyawan dalam mencari informasi yang berhubungan dengan cutinya.

\section{B. Batasan Masalah}

Mengingat banyaknya informasi yang disajikan dan Sistem informasi kepegawaian memiliki cakupan yang sangat luas, maka penulis melakukan penelitian sangat terbatas. Oleh karena itu penulis merasa perlu untuk melakukan pembatasan dalam skripsi ini sebagai berikut :

1. Pengolahan data hanya membahas proses pengolahan cuti karyawan.

2. Hanya membahas tentang proses pengajuan cuti karyawan, rekap cuti, laporan cuti, dan informasi masa cuti yang masih berlaku dan proses analisis terhadap data tersebut.

3. Sistem Informasi cuti karyawan ini hanya berlaku untuk karyawan PT. Colorpak Indonesia, Tbk.

\section{Rumusan Masalah}

Berdasarkan identifikasi masalah dan batasan masalah, maka rumusan masalah dalam penelitian ini adalah:

1. Bagaimana merancang bangun sistem informasi untuk pengajuan cuti karyawan?

2. Bagaimana merancang bangun sistem informasi berbasis web dengan memanfaatkan aplikasi PHP ?

\section{Tujuan dan Manfaat Penelitian}

Tujuan penelitian ini sebagai tersebut :

1. Merancang sistem informasi kepegawaian yang dapat memberikan kemudahan informasi kepada karyawan dalam mendapatkan hak cuti.

2. Merancang dan membuat sistem informasi cuti karyawan agar dapat membantu $H R D$ dalam mengelola data cuti karyawan secara maksimal.

3. Untuk mengetahui dan mengevaluasi sistem informasi cuti karyawan yang sedang berjalan sehingga dapat menghasilkan laporan dengan cepat dan akurat pada waktunya.

Manfaat yang diperoleh dari hasil penelitian ini adalah:

a. Manfaat Praktis

1. Memudahkan pegawai dalam mengakses sistem informasi 
kepegawaian cuti karyawan yang berbasis web

2. Lebih mudah mendapatkan informasi kepegawaian cuti karyawan dengan cepat.

b. Manfaat Teoritis

1. Memanfaatkan perkembangan teknologi berbasis web dengan optimal.

2. Agar informasi sistem kepegawaian cuti karyawan terdokumentasikan dengan baik.

\section{LANDASAN TEORI}

\section{A. Definisi Pegawai atau karyawan}

Karyawan adalah manusia yang menggunakan tenaga dan kemampuannya untuk mendapatkan balasan berupa pendapatan baik berupa uang maupun bentuk lainya kepada pemberi kerja atau pengusaha atau majikan (U.U No.13 Tahun 2003).

Berdasarkan sifat dan jangka waktu ikatan kerjanya, status pekerja dapat dikategorikan menjadi 2 (dua), yaitu : (UU No.13 Tahun 2003).

1. Pegawai Tetap

Pegawai Tetap adalah pekerja yang memenuhi kriteria penerimaan yang telah ditentukan, diterima, dipekerjakan dan memperoleh imbalan atas kontribusinya serta terikat pada hubungan kerja dengan instansi atau perusahaan yang tidak terbatas waktunya.

\section{Pegawai Kontrak}

Pegawai kontrak adalah pekerja yang terikat pada hubungan kerja dengan instansi atau perusahaan secara terbatas atas dasar kontrak atau perjanjian kerja untuk jangka waktu tertentu

\section{B. Definisi Cuti}

Menurut Peraturan Pemerintah Republik Indonesia No. 24 Tahun 1976 Bab 1 Pasal 1, menyatakan pengertian Cuti adalah keadaan tidak masuk kerja yang diizinkan dalam jangka waktu tertentu. Peraturan Pemerintah Republik Indonesia No. 24 Tahum 1976 Bab
II Pasal 3 menerangkan tentang macammacam cuti yaitu, sebagai berikut :

\section{Cuti Tahunan}

Setiap Pegawai Negeri Sipil yang telah bekerja sekurang-kurangnya satu tahun secara terus menerus berhak atas cuti tahunan. Lamanya cuti tahunan adalah 12 (dua belas) hari kerja. Cuti tahunan tersebut dapat diambil secara terpecahpecah, dengan ketentuan setiap bagian tidak boleh kurang dari 3 (tiga) hari kerja. Cuti tahunan yang tidak diambil dalam tahun yang bersangkutan dapat diambil dalam tahun berikutnya untuk paling lama 18 (delapan belas) hari kerja termasuk cuti tahunan dalam tahun yang sedang berjalan. Cuti tahunan yang tidak diambil dalam kurun waktu 2 (dua) tahun berturut-turut atau lebih, dapat diambil dalam tahun berikutnya untuk paling lama 24 (dua puluh empat) hari kerja, termasuk cuti tahunan dalam tahun yang sedang

2. Cuti Besar

Cuti besar adalah cuti yang dapat diambil oleh seorang PNS setelah bekerja 6 tahun berturut-turut. Lama cuti besar adalah maksimal 90 hari kalender.

3. Cuti Sakit

Cuti sakit adalah cuti yang bisa diambil oleh seorang PNS ketika sakit dan membutuhkan waktu istirahat untuk pemulihan kondisinya.

4. Cuti Bersalin

Cuti bersalin adalah cuti yang dapat diambil oleh PNS wanita untuk melahirkan anak pertama, kedua, dan ketiga. Lama cuti bersalin adalah maksimal 90 hari kalender.

5. Cuti Karena Alasan Penting

PNS dapat cuti karena alasan penting untuk paling lama 60 hari kalender. Lamanya cuti karena alasan penting hendaknya ditetapkan sedemikian rupa, sehingga benar-benar hanya untuk waktu yang diperlukan saja. Dalam kondisi tertentu, cuti alasan penting hanya bisa diambil setelah hak cuti pegawai yang bersangkutan tidak mencukupi lagi/habis. 
Selain dimuat di Peraturan Pemerintah Republik Indonesia, cuti juga dimuat pada Undang-Undang Ketenagakerjaan Bab X tentang perlindungan pekerja/buruh. Paragraf 1 Pasal 79 "Pengusaha wajib memberikan waktu istirahat dan cuti kepada pekerja / buruh. (UU No.13 Th:2003).

\section{Definisi Web Browser dan HTML}

Web Browser adalah aplikasi untuk menampilkan halaman yang berbentuk kode HTML. "HTML atau (Hypertext Mark Up Languange) adalah protokol yang digunakan untuk menstranfer data atau dokument dari web server ke web browser menurut Sibero (2011:11)). Sebagaimana kita ketahui, HTML (Hypertext Mark Up Languange) adalah standart untuk membuat halaman-halaman web. Semua halaman web ditulis dengan bahasa HTML. Walaupun beberapa file mempunyai ekstensi yang berbeda (contoh, html, php, php3), ouput file-file tersebut tetap HTML.

Dalam penggunaanya sebagian besar kode HTML tersebut terletak diantara tag container, yaitu diawali dengan nama tag dan diakhiri dengan nama tag (terdapat tanda “"”). Document HTML mempunyai tiga buah tag utama yang membentuk struktur dari dokument tersebut. Ketiga buah tag tersebut adalah Tag HTML, HEAD dan BODY.

Penjelasan :

a. HTML sebagai tanda awal dokumen HTML.

b. HEAD sebagai informasi page header. Didalam tag ini kita bisa meletakkan tagtag tittle, base, isi index, link, scrip, style, dan meta.

c. BODY, didalam tag ini bisa diletakkan berbagai atribut halaman seperti warna latar belakang, warna text, warna link, warna visited link, warna active dan lain-lain. Contoh atribut : color, background, text, link, vlink dan lain-lain.

Web adalah cara yang cukup efisien dan efektif dalam untuk publikasi atau komersialisasi suatu produk dari perusahaan.
Cara ini menjadi alternative yang menguntungkan jika kita bandingkan dengan cara tradisional yaitu melalui media masa seperti :koran, majalah, tv, dan radio yang membutuhkan investasi besar.

\section{Server HTTP Apache}

Server HTTP Apache atau Server $W e b / W W W$ Apache adalah server web yang dapat dijalankan di banyak sistem operasi (Unix, BSD, Linux, Microsoft Windows dan Novell Netware serta platform lainnya) yang berguna untuk melayani dan memfungsikan situs web. Protokol yang digunakan untuk melayani fasilitas $w e b / w w w$ ini menggunakan HTTP. Apache memiliki fitur-fitur canggih seperti pesan kesalahan yang dapat dikonfigur, autentikasi berbasis basis data dan lain-lain. Apache juga didukung oleh sejumlah antarmuka pengguna berbasis grafik (GUI) yang memungkinkan penanganan server menjadi mudah. Apache merupakan perangkat lunak sumber terbuka dikembangkan oleh komunitas terbuka yang terdiri dari pengembang-pengembang dibawah naungan Apache Software Foundation.

\section{E. Internet}

Menurut Sibero (2011:10) “Internet merupakan salah satu teknologi yang berkembang sangat pesat dan berskala global, Internet dapat juga dapat disebut jaringan alam suatu jaringan yang luas". Seperti halnya jaringan komputer lokal maupun jaringan komputer area, internet juga menggunakan protokol komunikasi yang sama yaitu ; TCP/IP (Transmission Control Protol /Internet Protokol). Kehadiran internet memberikan kemudahan dalam menerima dan mengakses informasi dalam berbagai format dari seluruh penjuru dunia." Setiap bagian akan dapat memasang informasinya dengan website atau homepagenya masing-masing. Sehingga setiap karyawan dapat mencari informasi yang dibutuhkannya, hal ini dapat meningkatkan produktifitas kerja.

\section{F. Definisi Mysql}

Menurut Aditya (2011:61), MySQL (My Structure Query Language) adalah sebuah 
perangkat lunak sistem manajemen basis data SQL (Database Management System) atau DBMS yang multithread, multi-user yang bersifat gratis dibawah lisensi GNU General Public Licence (GPL). MySQL memiliki beberapa keistimewaan, antara lain:

a. Portabilitas

b. Perangkat lunak sumber terbuka

c. Multi-user

d. Performance tuning

e. Ragam tipe data

f. Perintah dan Fungsi

g. Keamanan

h. Skalabilitas dan Pembatasan

i. Konektivitas

j. Lokalisasi

k. Antar Muka

1. Klien dan Peralatan

m. Stuktur table lain:

Beberapa kelebihan pada Mysql, antara

1. MySQL dapat berjalan dengan stabil pada berbagai sistem operasi, seperti Windows, Linux, FreeBSD, Mac Os $X$ Server, Solaris, dan masih banyak lagi.

2. Bersifat Open source, MySQL didistribusikan secara open source (gratis), dibawah lisensi GNU General Public Licence (GPL).

3. Bersifat Multiuser, MySQL dapat digunakan oleh beberapa user dalam waktu yang bersamaan tanpa mengalami masalah.

4. MySQL memiliki kecepatan yang baik dalam menangani query (perintah $S Q L$ ). Dengan kata lain, dapat memproses lebih banyak $S Q L$ persatuan waktu.

5. Dari segi security atau keamanan data, $M y S Q L$ memiliki beberapa lapisan sekuriti, seperti level subnet mask, nama host, dan izin akses user dengan sistem perizinan yang mendetail serta password yang terenkripsi.

\section{G. Hypertext Preprocessor}

Menurut Aditya $(2011,1)$ PHP: Hypertext Preprocessor yaitu bahasa scrip yang dapat ditanamkan atau disisipkan ke dalam HTML. PHP banyak dipakaki untuk memprogram situs web dinamis. PHP merupakan kependekan dari Personal Home Page (Situs personal). PHP pertama kali dibuat oleh Rasmus Lerdorf pada tahun 1995. Pada waktu itu PHP masih bernama form Interpreted (FI), yang wujudnya berupa sekumpulan skrip yang digunakan untuk mengolah data dormulir dari web. PHP merupakan salah satu bahasa script yang terbilang baru dan tersedia secara bebas dan masih memungkinkan untuk dikembangkankan lebih lanjut. PHP dapat diintegrasikan (embedded) ke dalam web server, atau dapat berperan sebagai program CGI yang terpisah. Karakteristik yang paling unggul dan paling kuat dalam PHP adalah lapisan integrasi database (database integration layer). Database yang didukung PHP adalah : Oracle. Adabas-D, Sybase, FilePro, mSQL, Velocis, MySQL, Informix, Solid, dBase, dll.

Rasmus merilis kode sumber tersebut untuk umum dan menamakannya PHP/FI.Maka banyak pemrogram yang tertarik ikut mengembangkan PHP. Pada November 1997, diliris PHP/FI 2.0. Pada liris ini, interpreter PHP sudah diimplementasikan dalam program C. Dalam liris ini disertakan juga modul-modul ekstensi yang meningkatakan kemampuan PHP/FI secara signifikan.

Pada tahun 1997, sebuah perusahaan bernama Zend menulis ulang interpreter PHP menjadi lebih bersih, lebih baik dan lebih cepat. Kemudian pada Juni 1998, perusahaan tersebut merilis interpreter baru untuk PHP dan meresmikan rilis tersebut sebagai PHP 3.0 dan singkatan PHP diubah menjadi akronim berulang PHP: Hypertext Preprocessing.

Beberapa kelebihan PHP dari bahasa pemrograman web, antara lain :

a. Bahasa pemrograman PHP adalah sebuah bahasa script yang tidak melakuakan sebuah kompilasi dalam penggunaanya.

b. Web Server yang mendukung PHP dapat ditemukan dimana-mana dari mulai apache, IIS, Lighttpd, hingga Xitami dengan konfigurasi yang relative mudah. 
c. Dalam sisi pengembangan lebih mudah, karena banyaknya milis-milis dan developer yang siap membantu dalam pengembangan.

d. Dalam sisi pemahaman, PHP adalah bahasa scripting yang paling mudah karena memiliki referensi yang banyak.

e. PHP adalah bahasa open source yang dapat digunakan diperbagai mesin (Linux, Unix, Macintosh dan Windows) dan dapat dijalankan secara runtime melalui console serta juga dapat menjalankan perintahperintah sistem.

\section{Apache Web Server}

Menurut Aditya (2011:3) "Apache Web Server merupakan program aplikasi yang berjalan di server, berfungsi untuk menjalankan aplikasi web sehingga bisa diakses oleh klien baik melalui jaringan intranet maupun internet".

\section{J. Dreamweaver}

Menurut Christianus Sigit (2010:1) "Dreamweaver adalah sebuah HTML editor profesional untuk mendesain web secara visual dan mengelola situs atau halaman web". Saat ini terdapat software dari kelompok Adobe yang belakangan banyak digunakan untuk mendesain suatu web. Versi terbaru dari Adobe Dreamwever CS3 memiliki beberapa kemampuan bukan hanya sebagai software untuk desain web saja, tetapi juga menyunting kode serta pembuatan aplikasi web. Antara lain: $J S P, P H P, A S P, X M L$, dan Cold Fusion. Dreamwever merupakan software utama yang digunakan oleh Web Desainer dan Web Programmer dalam mengembangkan suatu situs web. Hal ini disebabkan oleh ruang kerja, fasilitas, dan kemampuan Dreamwever yang mampu meningkatkan produktivitas dan efektivitas, baik dalam desain maupun membangun suatu situs web.

Dalam perkembangannya, Adobe Dreamwever telah mencapai versinya yang terbaru atau lebih dikenal dengan Adobe Dreamwever CS3. Fitur-fitur yang dimiliki semakin lengkap dan handal, untuk membuat pengguna Dreamwever CS53 semakin dapat berkreasi dan berinovasi dengan bebas dalam mendesain web. Fitur baru yang semakin handal untuk versi terbaru ini dimunculkan, diantaranya adalah Integrated CMS Support, CSS Inspection, PHP Custom Class Code Hinting, dan Site-Specific Code Hinting. Semua fitur baru tersebut semakin memantapkan pengguna Adobe Dreamwever CS3 untuk semakin mengeksplorasi dan mengeksploitasi ide kreasi pengolahan website.

\section{K. Fasilitas Dreamweaver}

Menurut Christianus Sigit (2010:1), Dreamwever CS3 memiliki peningkatan kemampuan toolbar, yaitu Dreamwever CS3 dapat digunakan untuk meodifikasi tampilan toolbar atau menambahkan fungsi baru. Selain user interface baru, Dreamwever CS3 memiliki kemampuan untuk menyunting kode dengan lebih baik. Dreamwever CS3 juga dapat melakukan print kode pada jendela Code View, serta memiliki fasilitas Code Hints yang membantu dalam urutan tag-tag, serta Tag Inspector yang sangat berguna dalam menangani tag-tag HTML.

Komponen-komponen yang terdapat di dalam ruang kerja Adobe Dreamweaver CS3 adalah:

a. Insert Bar, berisi tombol-tombol untuk menyisipkan berbagai macam objek seperti: image, tabel, dan layer ke dalam dokumen.

b. Document Toolbar, berisi tombol-tombol dan menu pop-up yang menyediakan tampilan berbeda dari jendela dokumen.

c. Coding Window, berisi kode-kode HTML dan tempat untuk menuliskan kode-kode pemrograman, misalnya PHP atau ASP.

d. Panel Group, adalah kumpulan panel yang saling berkaitan satu sama lainnya yang dikelompokkan di bawah satu judul.

e. Property Inspector, digunakan untuk melihat dan mengubah berbagai properti objek atau teks.

f. Jendela Dokumen, berfungsi untuk menampilkan dokumen di mana anda sekarang bekerja. 
g. Ruler, mempermudah ukuran dalam mendesain halaman web.

h. Site Panel, digunakan untuk mengatur filefile dan folder-folder yang membentuk situs web.

\section{Model Waterfall}

Menurut Pressman (2010:29-47), ada beberapa model proses software yang umum digunakan, salah satunya adalah model sekuensial linear model. Sekuensial linear ini juga dikenal dengan nama " Classic Life Cycle" atau Waterfall Model. Model ini meliputi beberapa tahapan seperti dilihat pada gambar di bawah ini :

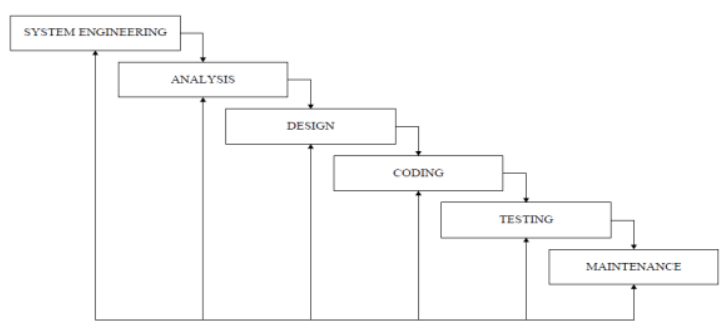

Sumber : Pressman, 2010

Gambar 2.1 Model Waterfall

\section{System Engineering}

Yaitu tahap dimana semua pekerjaan dan aktivitas yang dikerjakan sebelum aplikasi dibangun dan digunakan oleh user tahap untuk mengadakan pengumpulan data dengan melakukan pertemuan dengan customer, maupun mengumpulkan datadata tambahan baik yang ada di jurnal, artikel, maupun dari internet.

2. Analysis

Proses analisis merupakan lanjutan dari proses System Engineering. Tahapan ini akan menghasilkan dokumen user requiremen atau bias dikatakan sebagai data yang berhubungan dengan keinginan user dalam pembuatan software, termasuk rencana yang akan dilakukan.

3. Desain

Proses desain ini akan menerjemaahkan syarat kebutuhan ke sebuah perancangan software yang dapat diperkirakan sebelum dibuat coding, proses ini berfokuspada rancangan struktur data, arsitektur software, representasi interface, dan detail (algoritma) procedural. Tahapan ini menghasilkan dokumen yang disebut software requiremen.

4. Conding

Conding merupakan proses membuat kode, coding atau pengkodean merupakan penerjemaah desain dalam bahasa yang biasa dikenali oleh komputer. Programmer akan menerjemaahkan transaksi yang diminta oleh user. Tahapan inilah yang merupakan tahapan secara nyata dalam mengerjakan suatu software, artinya penggunaan komputer akan dimaksimalkan dalam tahapan ini.

5. Testing

Pada tahap ini akan dilakukan testing atau pengujian program secara keseluruhan dari aplikasi system dengan tujuan dari tahap ini adalah untuk memastikan agar aplikasi ini sudah benar-benar layak untuk digunakan oleh user.

\section{Maintenance}

Tahapan ini bias dikatakan final dalam pembuatan sebuah software atau system. Setelah melakukan analisis, desain dan pengkodean maka system yang sudah jadi akan digunakan oleh user, kemudian software yang telah dibuat harus dilakukan pemeliharaan secara berkala.

\section{METODOLOGI PENELITIAN}

\section{A. Metode Pengumpulan Data}

Untuk mendapatkan data yang diperlukan dalam penulisan laporan tugas akhir ini penulis menggunakan dua jenis data pada penelitian, antara lain:

1. Data Primer, merupakan sumber data yang diperoleh secara langsung dari sumber aslinya (tidak melalui media perantara).

\section{a. Metode Observasi (Observation Research)}

Tahap ini merupakan tahap pengumpulan informasi mengenai kebutuhan sistem yang sedang berjalan di PT. Colorpak Indonesia, Tbk khususnya di Divisi Human Resource Development dengan cara observasi di tempat penelitian. Hal ini perlu 
diadakan agar penulis dapat melakukan analisis terhadap sistem informasi kepegawaian cuti karyawan.

b. Metode Wawancara (Interview Research)

Wawancara dilakukan dengan cara mewawancarai langsung pihak-pihak terkait yaitu Ibu Dini Astriani, SE, Msi sebagai kepala kepegawaian/HRD, dan Bapak Nanan Dachlan dan ibu Siti Khodjah yang sebagai user atau pegawai/karyawan, yang berguna untuk mendapatkan informasi maupun data-data yang dibutuhkan untuk perancangan sistem yang akan dibangun.

2. Data Sekunder, yaitu merupakan sumber data penelitian yang diperoleh secara tidak langsung melalui media perantara (diperoleh dan dicatat oleh pihak lain).

a. Metode Pustaka (Library Research)

Sumber dokumen-dokumen yang penulis gunakan untuk mendapatkan informasi dari metode ini adalah dari pencarian referensi-referensi dari internet dan dari buku-buku yang berhubungan dengan topik pembahasan untuk melengkapi informasi yang dibutuhkan oleh penulis.

Untuk melengkapi dan mendukung materi dalam uraian pembahasan, dibutuhkan sejumlah data atau informasi yang berkaitan dengan penelitian karya ilmiah ini. Oleh karena itu, penulis melakukan penelitian guna mendapatkan data yang real sesuai referensi yang diperlukan. Esensial dalam metode ini bertujuan untuk melengkapi proses penelitian selanjutnya, metode ini meliputi penelitian lapangan (observasi dan wawancara), dan studi pustaka.

\section{HASIL DAN PEMBAHASAN}

\section{A. Profil Responden}

Sistem informasi kepegawaian cuti karyawan pada PT. Colorpak Indonesia, Tbk saat ini hanya bersifat kondisional dan kurang optimal. Pada saat informasi kepegawaian cuti karyawan masih menggunakan Ms. Excel, untuk mendapatkan data cuti karyawan harus membuka lembaran arsip. Cara ini memakan waktu yang cukup lama serta tidak efektif dan efisien.

Dalam mendapatkan laporan data kepegawaian cuti karyawan, pihak manager memperoleh data tersebut dari staff HRD dan dengan menggunakan MS. Excel. Laporan ini nanti akan dicetak dan akan diarsipkan.

\section{B. Prosedur Sistem Berjalan}

Prosedur sistem adalah suatu prosedur atau tahap-tahap yang dilakukan sebelum memulai kegiatan untuk menyelesaikan suatu pekerjaan.

Prosedur pengajuan cuti di PT.Colorpak Indonesia, Tbk dilakukan secara manual baik dilakukan di dalam maupun di luar kantor. Terdapat beberapa tahap yang harus dilalui oleh karyawan sesuai dengan ketentuan yang telah ditetapkan adalah sebagai berikut :

1. Karyawan yang akan melakukan cuti harus mengajukan surat permohonan kepada pihak HRD selambat-lambatnya 15 hari sebelum cuti diberikan.

2. Surat pengajuan diberikan kebagian kepegawaian.

3. Bagian Kepegawaian dan Manager sub divisi memproses otorisasi perijinan sesuai dengan ketentuan yang ditetapkan.

4. Bagian kepegawaian mengeluarkan list perizinan cuti baik diterima atau tidaknya dengan proses yang sudah ditetapkan oleh perusahaan. 


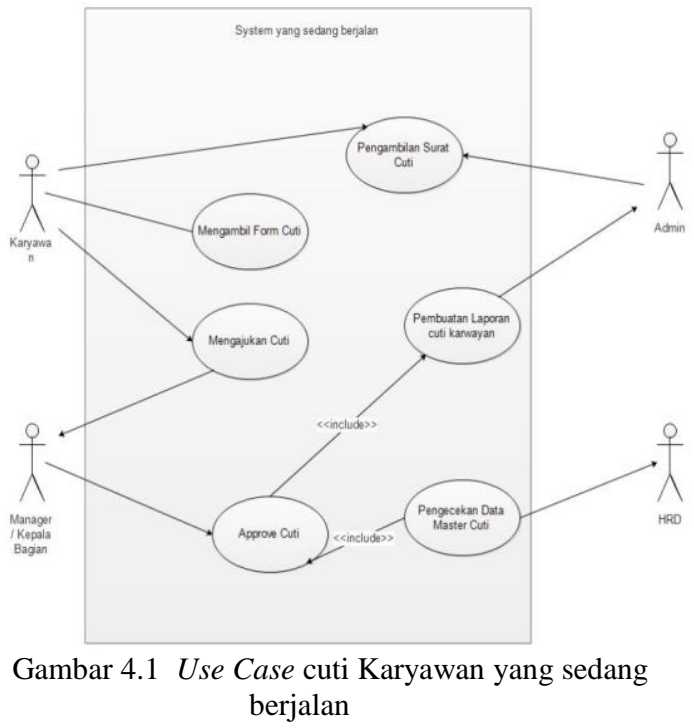

C. Activity Diagram Proses Cuti Karyawan yang sedang berjalan

Prosedur standar yang akan dijelaskan merupakan prosedur perencanaan yang melibatkan beberapa bagian yang digambarkan dalam bagan alur (activity diagram) berikut ini

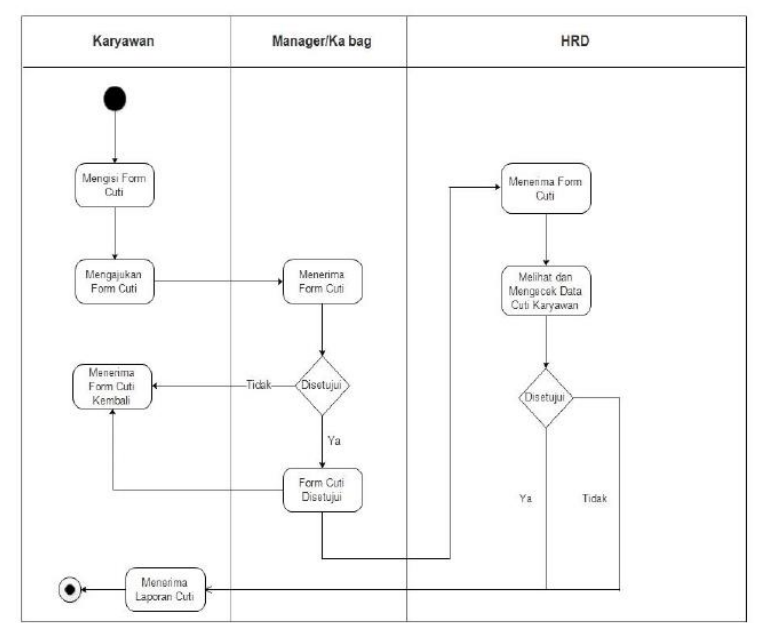

Gambar 4.2 Activity Diagram proses cuti karyawan yang sedang berjalan

\section{Analisis Kebutuhan Sistem}

Penelitian ini menggunakan metode pengembangan sistem dengan Metode Waterfall. Proses pertama dalam pengembangan sistem dengan Metode Waterfall, yaitu adalah proses perancangan sistem (System Engineering), dimana penulis mengumpulkan informasi kebutuhan user atau pihak PT. Colorpak Indonesia, Tbk terhadap perangkat lunak yang akan dibuat berdasarkan permasalahan yang ada pada analisa sistem yang berjalan.

\section{E. Use Case Diagram Penggunaan Fitur Umum \\ 1. HRD dan Karyawan}

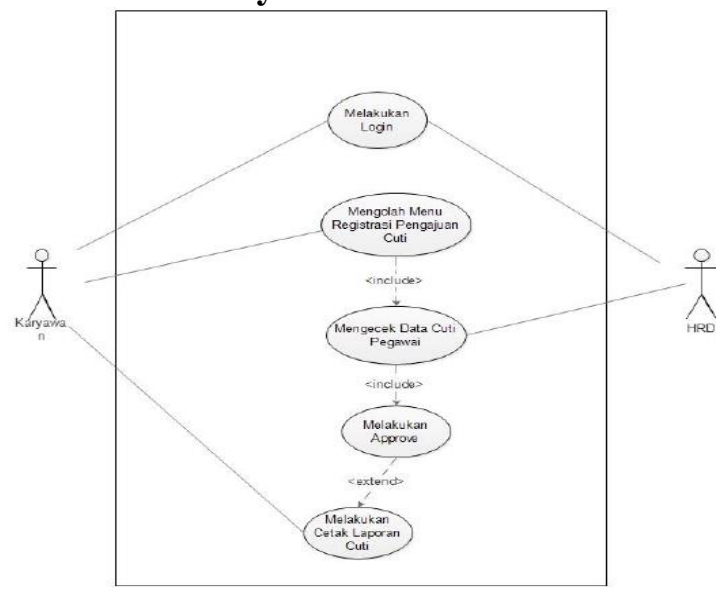

Gambar 4.3 Use Case fungsi utama HRD dan Karyawan

\section{Admin}

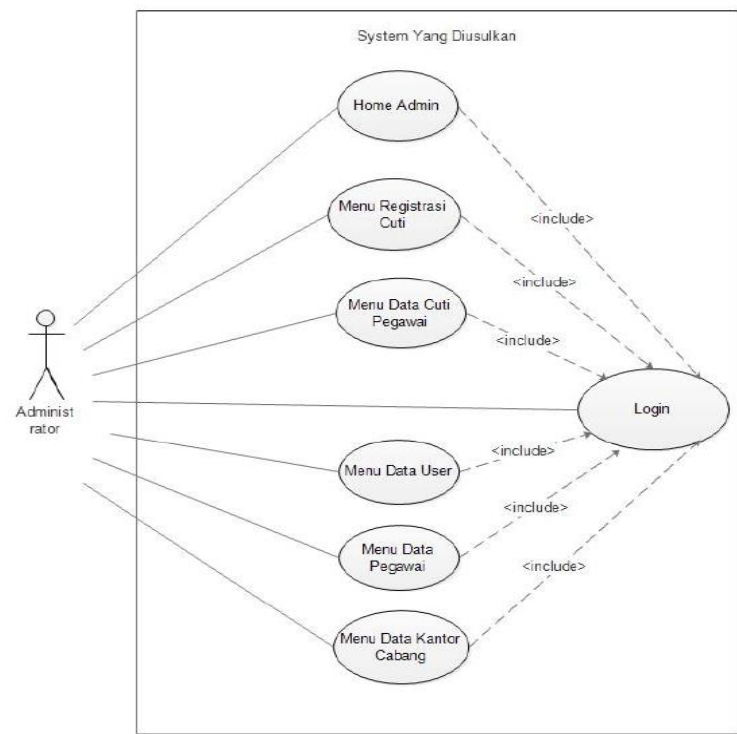

Gambar 4.4 Usecase fungsi Pengelola Sistem (Admin)

\section{F. Desain Sistem}

Berdasarkan rekomendasi hasil dari analisis sistem, maka analis sistem harus memikirkan bagaimana membentuk dan 
mengembangkan sistem tersebut. Berikut ini adalah graphical user interface (GUI) yang dirancang untuk aplikasi sistem informasi kepegawaian cuti karyawan, yaitu:

a. Tampilan Login
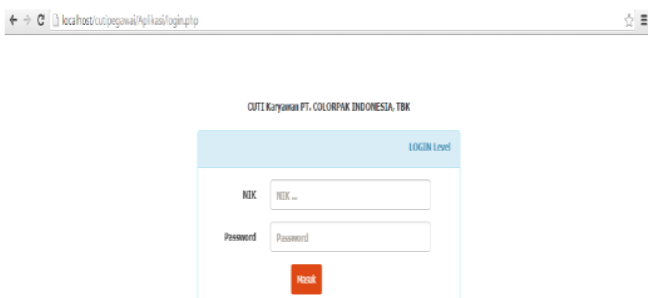

Gambar 4.5 Tampilan Login

b. Tampilan Menu Home Administrator

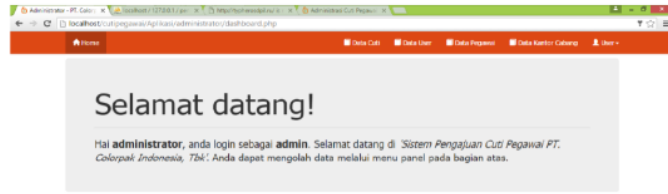

Gambar 4.6 Tampilan Menu Home Administrator

c. Tampilan Menu Registrasi Cuti

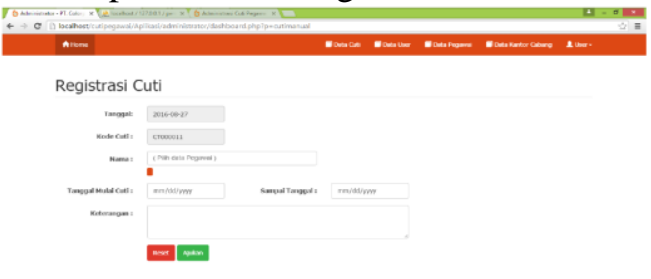

Gambar 4.7 Tampilan Menu Registrasi Cuti

\section{d. Tampilan Menu History Cuti}

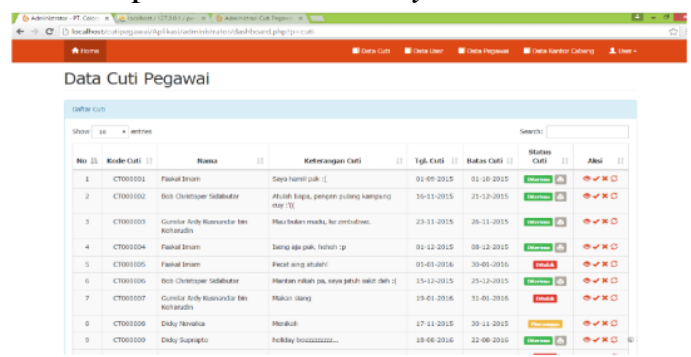

Gambar 4.8 Tampilan Menu History Cuti e. Tampilan Menu Data User

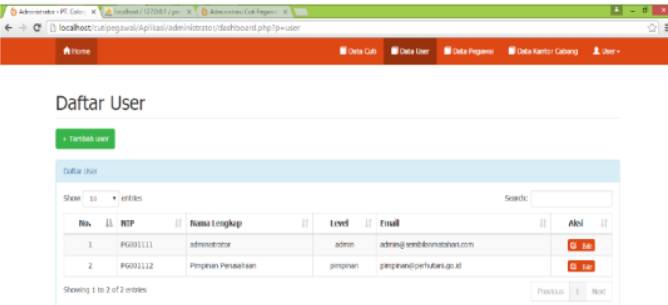

Gambar 4.9 Tampilan Menu Data User

f. Tampilan Menu Data Pegawai

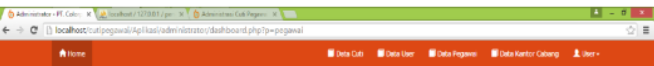

Daftar Pegawai

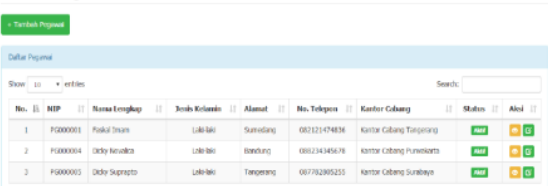

Gambar 4.10 Tampilan Menu Data Pegawai

g. Tampilan Menu Data Kantor Cabang

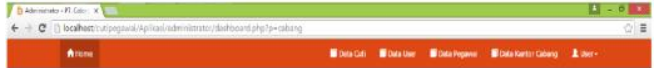

Kantor Cabang PT. Colorpak Indonesia, Tbk

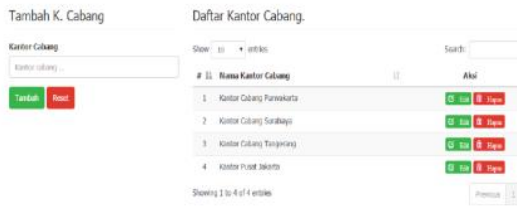

Gambar 4.11 Tampilan Menu Data Kantor Cabang

h. Tampilan Menu Ubah Password

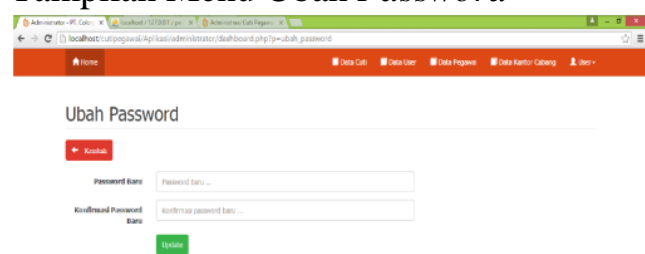

Gambar 4.12 Tampilan Menu Ubah Password

i. Tampilan Menu Registrasi Cuti 


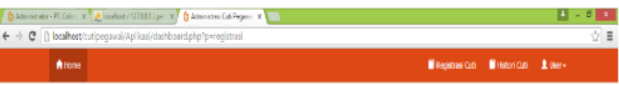

Registrasi Cuti

$+\mathrm{xmat}$

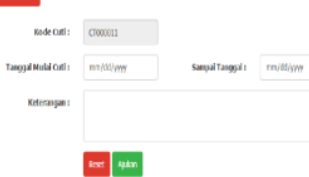

Gambar 4.13 Tampilan Menu Registrasi Cuti

j. Tampilan Menu History Cuti

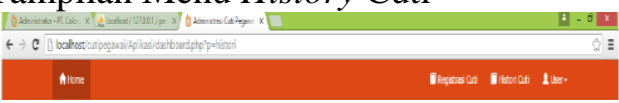

Histori Cuti

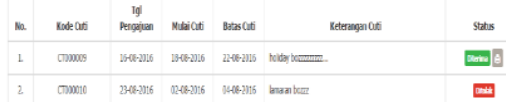

Gambar 4.14 Tampilan Menu History Cuti

k. Tampilan Menu Cetak Laporan Cuti

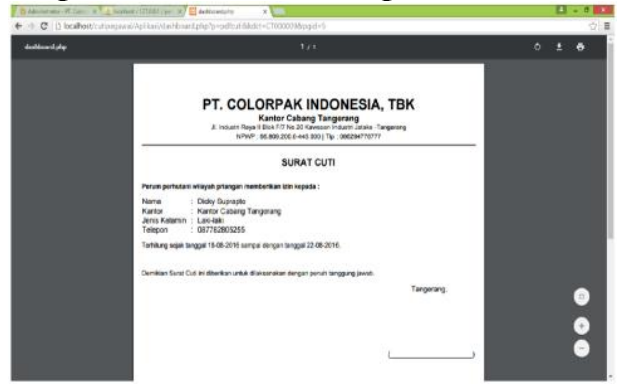

Gambar 4.15 Tampilan Menu Cetak Laporan Cut

1. Tampilan Menu Update Data Pribadi

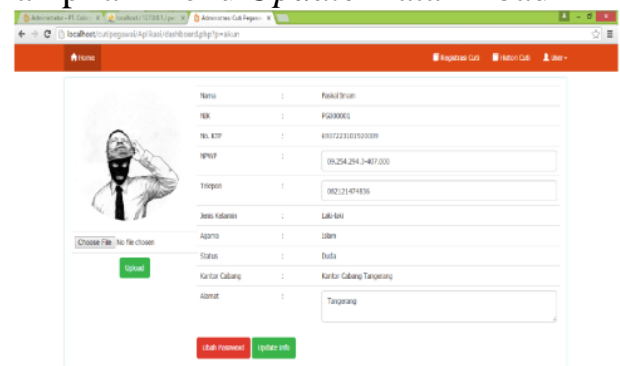

Gambar 4.16 Tampilan Menu Update Data Pribadi

m. Tampilan Menu Home Pimpinan/HRD

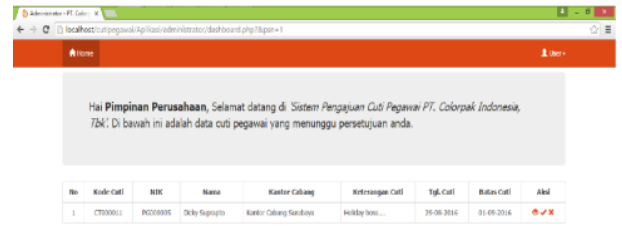

Gambar 4.17 Tampilan Menu Pimpinan/HRD

n. Tampilan Menu Menerima Pengajuan Cuti

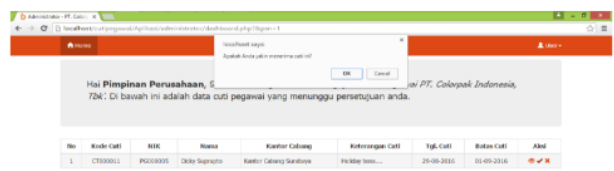

Gambar 4.18 Tampilan Menu Menerima Pengajuan Cuti

o. Tampilan Menu Menolak Pengajuan Cuti

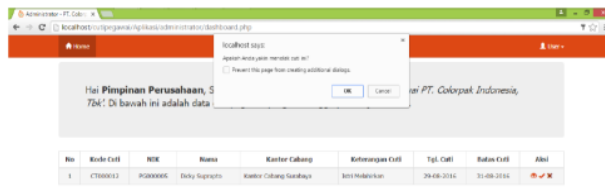

Gambar 4.19 Tampilan Menu Menolak Pengajuan Cuti

p. Tampilan Menu Melihat Data dan Histori Karyawan

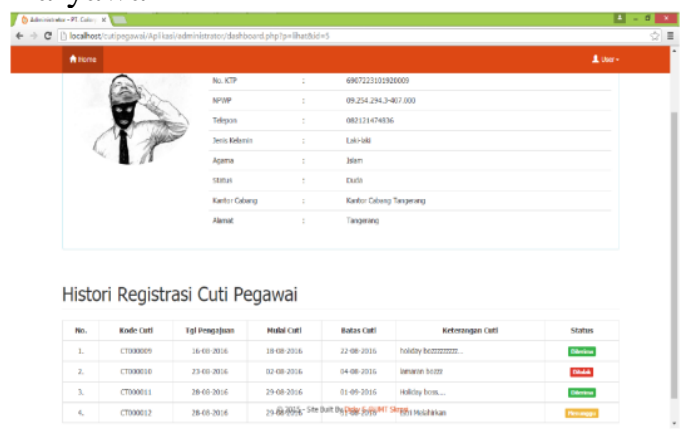

Gambar 4.20 Tampilan Menu Melihat Data dan Histori Karyawan

\section{KESIMPULAN}

Hasil dari rancang bangun sistem informasi untuk mendukung proses pengajuan cuti menunjukkan adanya 
efesiensi dan efektifitas serta perubahan mendasar yang dapat dicapai. Aplikasi yang diusulkan oleh penulis, diharapkan dapat membantu Karyawan, Pimpinan/HRD pada PT. Colorpak Indonesia, Tbk. untuk proses pengajuan cuti karyawan dengan mudah, serta mengolah data karyawan seperti: menyimpan, mencari, mengubah, dan cetak laporan data cuti karyawan menjadi lebih cepat karena data cuti karyawan mudah untuk dicari dan diakses setiap saat.

Dalam proses pengajuan cuti dan penginputan data karyawan dapat langsung diakses dari komputer melalui sistem informasi kepegawaian yang sudah berbasis web.

\section{REFERENSI}

[1]. Aditya, Alan Nur. 2011. Jago PHP \& MySQL Dalam Hitungan Menit. Jakarta: Dunia Komputer.

[2]. Alexander F. K. Sibero. 2011. Kitab Suci Web Programing, MediaKom, Yogyakarta.

[3]. Peraturan Pemerintah Nomor 24 Tahun 1976 Tanggal 23 Desember 1976 Tentang cuti pegawai

[4]. Pressman, Roger S. 2010. Rekayasa Perangkat Lunak Edisi 7 : Buku 1

[5]. Setiyanto Arif, Samopa Febriliyan, Alwi (2013) Pembuatan Sistem Informasi Cuti pada Kantor Pelayanan Perbendaharaan Negara dengan menggunakan Mysql dan PHP. Jurnal Teknil Pomits Vol 2, No.2 ISSN : 2337-3539

[6]. Sigit, Christianus. 2010. Mudah Membuat Toko Online Dengan OsCommerce. Yogyakarta. Andi 